\title{
Field assessment for photovoltaic array as herbal plots based on bioactive compounds analysis
}

\begin{abstract}
Introduction of renewable energy resources especially Solar Photovoltaic (PV) supports the green economy requirements. Solar PV technologies have become the most prominent green energy resources towards Malaysia energy mix by the year 2020. Despite the significant reduction of carbon emission, Solar PV farm requires a huge open area for electricity generation and furthermore, the space under each of the PV arrays are not utilised for any economical activities. This study extents the potentials PV arrays as herbal plots with Orthosiphon Stamineus deposited directly under the array structures without any disturbances to the PV operation. The aims of this work are to conduct sampling tests to determine the yield of crude extraction from the herbs by using the soxhlet extraction method, characterizing the phenolic compound and identifying the potential of bioactive compound from the extracts. Laboratory result shows that the highest crude extraction was $16.992 \%$ which is at par with samples from naturally grown locations. The highest Total Phenolic Content (TPC) of extract are recorded at $844.83 \mathrm{GAE} / 100 \mathrm{~g}$ by using 70:30 ratio of methanol to water concentration ratio and 720 minutes of extraction time.
\end{abstract}

Keyword: PV herbal plots; Orthosiphon stamineus; Total phenolic content; Proximate analysis; Bioactive compounds 